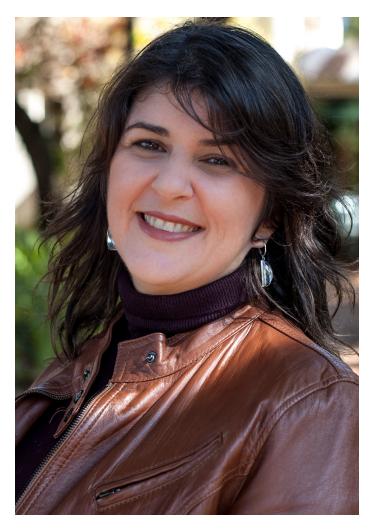

\title{
Paradigma do Recovery como orientador de políticas e práticas em saúde mental
}

O paradigma do recovery vem sendo cada vez mais adotado em diferentes países como diretriz das políticas e ações em saúde mental. No Brasil, a discussão sobre recovery ainda é insipiente. Apesar de a literatura brasileira trazer algumas traduções para o termo, como "superação", "recuperação" ou "restauração"1,2, usaremos aqui a palavra recovery em inglês, considerando ser esta a versão mais conhecida.

O movimento de recovery teve início na década de 80 do século $\mathrm{XX}$, a partir do movimento de usuários de serviços de saúde mental. Chamava a atenção de gestores e profissionais para a importância de reconhecer a experiência e conhecimento dos usuários de serviços e de seus cuidadores para o planejamento e desenvolvimento de ações.

O recovery seria um processo concreto e prático, em que indivíduos que necessitam de cuidados em saúde mental ganham e mantém melhor controle sobre suas vidas ${ }^{3}$. É compreendido como o processo de restaurar um sentido significativo de pertencimento à comunidade e senso positivo de identidade, reconstruindo a vida, apesar ou mesmo com as limitações impostas pela condição ${ }^{4}$. Pessoas que apresentavam comorbidades entre transtornos psiquiátricos e uso problemático de drogas descreveram o processo do recovery como um aprendizado sobre o manejo de eventos dolorosos da vida, culminando na experiência de voltar a se sentir útil e aceito, desenvolver o amor próprio, ter domínio sobre sua vida, ganhar controle sob o uso de substâncias e manejar os transtornos mentais ${ }^{5}$.

Apesar do processo de recovery ser individual, considera-se que as políticas, serviços e práticas podem favorecê-lo, construindo um ambiente que suporte o recovery. Nesta direção, há atualmente orientações para gestores e profissionais construírem práticas orientadas ao recovery ${ }^{6}$. Estas práticas estariam voltadas à promoção da esperança, autonomia e autodeterminação, visando construir parcerias colaborativas entre profissionais e usuários e reconhecendo a importância das redes de apoio e dos outros significativos, aproximando-os do tratamento. Práticas orientadas ao recovery também enfatizam e auxiliam a construir recursos pessoais e relacionais, compreendendo o indivíduo de modo holístico e singularizado, respeitando a diversidade e incentivando a participação comunitária e cidadania. Serviços que se orientam por este paradigma incentivam a reflexividade profissional e o feedback dos usuários, buscando autoavaliação constante.

Neste número, um dos estudos nos oferece elementos para avaliar como nossos serviços ainda se pautam por práticas que são contrárias ao recovery. Os pesquisadores entrevistaram profissionais da Estratégia de Saúde da Família, buscando conhecer as concepções destes sobre o trabalho em saúde mental. Identificaram que o foco do atendimento era a prescrição de medicamentos e que havia fragmentação do usuário por especialidades e serviços. Concluíram ressaltando a importância da responsabilização do profissional, da intersetorialidade e multidisciplinaridade. Entretanto, para que os serviços adotem práticas que auxiliem as pessoas no processo de recovery, faz-se necessária a formação de gestores e profissionais. Um dos estudos deste número destaca a importância de que gestores conheçam sobre as políticas em saúde mental e outro estudo discute a formação do enfermeiro para o trabalho na área de drogas.

A visão tradicional do tratamento em saúde mental coloca-o com um conjunto de técnicas e métodos que levariam à mudança, sem necessidade de que os usuários expusessem seus pontos de vista ${ }^{3}$. Por outro lado, 
o paradigma do recovery considera que o usuário deve ser ouvido em suas singularidades e que participe ativamente da construção do projeto terapêutico. Nesta direção, um dos estudos publicados neste número procurou compreender as motivações de idosos para o consumo de drogas. Dentre os motivos para o uso de drogas, os autores verificaram a busca por vínculos e para aceitar as mudanças ocorridas na vida. Foi destacada a importância de ouvir os idosos, conhecer suas singularidades e necessidades. Como referido anteriormente, práticas orientadas ao recovery investem na formação e suporte às redes de apoio. Neste número, em um dos estudos, os autores verificaram que familiares de pessoas com esquizofrenia sentiam-se sobrecarregados e vivenciavam significativos conflitos no convívio diário, precisando de apoio e orientação. A família também teve destaque em outro estudo publicado aqui, em que os autores encontraram que o apoio social e familiar tem relação positiva com a resiliência, podendo, portanto diminuir o impacto de situações precoces de estresse.

Em saúde mental, o paradigma do recovery dá centralidade à qualidade de vida do indivíduo, para além de seus sintomas e diagnóstico. As práticas orientadas ao recovery visam auxiliar o usuário de serviços a construir e manter uma vida significativa e satisfatória. Para isto, faz-se necessário o suporte de estudos que deem luz aos diferentes fatores do recovery e promovam embasamento científico para capacitações e formações na área.

\section{Referências}

1. Miranda AMP, Pimentel FA, Villares, CC. "Anjos de uma asa só": processos de superação na esquizofrenia em um grupo de ajuda mútua. Nova Perspectiva Sistêmica. 2014;(48):64-79.

2. Baccari IOP, Campos RTO, Stefanello S. Recovery: revisão sistemática de um conceito. Cien Saude Cole. 2015; 20(1):125-36.

3. Amering M, Schmolke M. Recovery in Mental Health: Reshaping Scientific and Clinical. Responsibilities. Reino Unido: Wiley-Blackwell; 2009.

4. Brekke E, Lien L, Biong S. Experiences of Professional Helping Relations by Persons with Co-occurring Mental Health and Substance Use Disorders. Int J Ment Health Addict. 2018;16(1):53-65.

5. Brekke E, Lien E, Davidson L, Biong S. First-person experiences of recovery in co-occurring mental health and substance use conditions. Adv Dual Diagn. 2017; 10(1):13-24.

6. Department of Health. Victoria: Mental Health, Drugs and Regions Division, Victorian Government. Framework for recovery-oriented practice. 2011. 34p.

\section{Clarissa Mendonça Corradi-Webster}

Editora Associada da SMAD, Revista Eletrônica Saúde Mental Álcool e Drogas, Professora Doutora da Faculdade de Filosofia, Ciências e Letras de Ribeirão Preto da Universidade de São Paulo. E-mail: clarissac@usp.br 